\title{
PENGEMBANGAN LEMBAR KEGIATAN PESERTA DIDIK UNTUK MENILAI UPAYA KONSERVASI KURA-KURA
}

\author{
Intan Indah Sari ${ }^{1 *}$, Aceng Ruyani ${ }^{1}$, dan Ariefa P. Yani ${ }^{1}$ \\ ${ }^{1}$ Program Studi Pendidikan Biologi, Fakultas Keguruan dan Ilmu Pendidikan, Universitas Bengkulu \\ email :intanindah.a1d014005@yahoo.com
}

\begin{abstract}
Abstrak
Tujuan penelitian ini adalah menganalisis kelayakan pengembangan Lembar Kegiatan Peserta Didik (LKPD) konservasi kura-kura pada materi identifikasi ancaman populasi dan menilai upaya konservasi. Metode penelitian adalah kuantitatif deskriptif. Penilaian perilaku konservasi peserta didik menggunakan angket konservasi kura-kura diberikan pada pembelajaran dengan strategi indooroutdoor. Hasil penelitian menunjukkan bahwa validasi LKPD pengembangan dengan persentase 92,5\% memiliki kriteria "sangat valid" dan terjadi peningkatan perilaku konservasi kura-kura peserta didik sebesar 27,03 \%. Kesimpulan dari hasil penelitian ini adalah LKPD pada materi identifikasi ancaman populasi hasil pengembangan sangat layak diujicoba dan efektif untuk meningkatkan upaya konservasi kura-kura bagi peserta didik.
\end{abstract}

Kata kunci: Kura-kura Sumatera, lembar kerja peserta didik

\begin{abstract}
This research aims to analyze the feasibility of a developed student worksheet (LKPD) on the conservation of Sumatran turtle, in the topic of identification of populations threat and assessment the conservation efforts of the students to the tortoise. The research is a quantitative descriptive. Assessment of conservation behavior of students was conducted using a turtle conservation questionnaire provided with indoor-outdoor-indoor as learning strategy. The result showed the developed LKPD was classified as very valid (percent of satisfaction=92.5). This LKPD was also valid to increase behavior of the learners in turtle conservation. As a conclusion, the developed LKPD is well worth and can be implemented as a learning resources to increase the conservation efforts of the students.
\end{abstract}

Keywords: Sumatran turtle, student worksheet 


\section{PENDAHULUAN}

Provinsi Bengkulu memiliki banyak ragam satwa liar dan sumber daya alam yang melimpah, baik sumber daya alam perairan maupun daratan. Salah satu satwa liar tersebut adalah kura-kura. Kurakura adalah hewan bersisik, dan berkaki empat yang termasuk golongan reptil. Ada 10 jenis Kura-kura yang terdapat di Bengkulu. Pada zaman perkembangan teknologi, pendidikan, kuliner dan lain sebagainya seperti sekarang, masyarakat mencari kura-kura sebagai penghasilan tambahan (Ruyani, 2009).

Kura-kura termasuk dalam kelas reptilia, ordo testudine. Kura-kura pertama muncul di bumi lebih dari 200 juta tahun yang lalu dalam periode Triassic. Kura-kura memiliki tengkorak primitif dengan kranium yang solid serta memiliki perisai. Kura-kura dapat ditemukan di air tawar, air laut maupun darat. Tubuh kura-kura dilindungi oleh cangkang atau perisai pada bagian punggung dan bagian perut. Perisai bagian atas atau bagian punggung disebut karapaks, sedangakan bagian bawah atau perut disebut plastron. Karapaks dan plastron tersusun atas beberapa pelat yang menanduk dengan bentuk dan ukuran yang bervariasi (Wiryono dkk., 2016).

Saat ini keberadaan kura-kura semakin terancam oleh aktivitas manusia. Paling nyata adalah konsumsi daging dan telur kura-kura. Beberapa spesies kura-kura dibunuh untuk produksi non-makanan. Perdagangan hewan peliharaan dapat menghilangkan beberapa spesies kurakura dari populasi dan dalam beberapa tahun belakangan ini semakin hebat. Spesies eksotik telah dieksploitasi untuk tujuan perdagangan (Sinaga, 2008).

Ancaman utama keanekaragaman hayati disebabkan oleh manusia yaitu perusakan habitat, fragmentasi habitat, gangguan pada habitat, pengunaan spesies yang berlebihan untuk kepentingan manusia, introduksi spesies eksotik dan penyebaran penyakit. Ancaman keanekaragaman hayati tersebut, disebabkan oleh penggunaan kekayaan alam yang semakin meningkat dengan semakin bertambahnya populasi manusia di muka bumi (Sinaga, 2008).

$\begin{array}{ccr}\text { Konservasi } & \text { merupakan upaya } \\ \text { pelestarian } & \text { lingkungan } & \text { dengan } \\ \text { memperhatikan manfaat yang dapat }\end{array}$
diperoleh pada saat ini dan tetap mempertahankan keberadaan setiap komponen lingkungan untuk pemanfaatan dimasa datang. Konservasi memiliki 2 bentuk, in situ dan konservasi ex situ. Konservasi in situ adalah pemeliharaan atau penangkaran satwa liar di habitat alam atau aslinya. Sedangkan, konservasi ex situ adalah pelestarian makhluk hidup di luar habitat aslinya (KEMENHUT, 2012).

Konservasi memiliki beberapa tujuan diantaranya: 1). Memelihara maupun melindungi tempat-tempat yang dianggap berharga supaya tidak hancur, berubah atau punah; 2). Melindungi benda-benda cagar alam yang dilakukan secara langsung yaitu dengan cara membersihkan, memelihara dan memperbaiki baik itu secara fisik maupun secara langsung dari pengarauh berbagai macam faktor, misalnya seperti faktor lingkungan yang bisa merusak benda-benda tersebut; dan 3). Melindungi sepesies flora dan fauna yang langka atau hamper punah, sehingga dapat menye-lamatkan spesies flora dan fauna tersebut dari kepunahan (Rahmi, 2008).

Upaya konservasi kura-kura telah dilakukan di Universitas Bengkulu di kolam Taman Pintar, Turtle Learning Center (TLC), dan kolam Pipi Putih. Terdapat 5 jenis kurakura yang dikonservasi di Universitas Bengkulu yaitu, Pipi Putih (Siebenrockiella crassiocollis), Garis hitam (Cyclemys oldhamii), Batok (Cuora amboinensis), Baning (Manouria emys), Duri/Nanas (Heosemys spinosa) (Suhartoyo, 2016). 
Berdasarkan wawancara peneliti mengenai kura-kura dan bahan ajar di SMA Negeri 8 Kota Bengkulu, hanya beberapa peserta didik saja yang mengenal kurakura. Kebanyakan peserta didik hanya melihat kura-kura di acara stasiun televisi, dan di pasar. Guru biologi di sekolah ini belum pernah membuat lembar kegiatan peserta didik (LKPD) yang berisikan materi tentang konservasi terutamanya konservasi kura-kura. Para guru masih menggunakan bahan ajar siap pakai yang dibeli oleh penyalur.

Berdasarkan hal tersebut maka peneliti mengembangkan suatu bahan ajar LKPD pada materi identifikasi ancaman populasi dan upaya konservasi kura-kura dengan mengangkat judul penelitian "Pengembangan Lembar Kegiatan Peserta Didik (LKPD) SMA Melalui Kegiatan IndoorOutdoor-Indoor (IOI) Untuk Menilai Hasil Belajar Pada Materi Identifikasi Ancaman Populasi Dalam Upaya Konservasi KuraKura".

Penelitian ini menggunakan kegiatan Indoor-Outdoor-Indoor (IOI). IOI merupakan kegiatan pembelajaran di dalam kelas kemudian peserta didik di ajak ke luar kelas dan kembali ke dalam kelas. Kegiatan pembelajaran IOI yang melibatkan lingkungan terbuka bersifat konkret sehingga diharapkan menjadikan pembelajaran dapat lebih bermakna. Kegiatan pembelajaran IOI ini dilakukan di sekolah dan juga di tempat konservasi kura-kura di Universitas Bengkulu.

Proses pembelajaran di kelas (indoor) memiliki kelebihan: (1). Tidak terhambat oleh cuaca; dan (2). Tidak terpengaruh oleh keadaan diluar kelas, misalnya kebisingan. Sedangkan kekurangannya: (1). Suasana cenderung formal dan membosankan sehingga siswa tidak begitu bebas berekspresi dan berkreasi; dan (2). Dibatasi dengan ruang kelas yang sempit (Silvia, 2015). Pada pembelajaran outdoor dapat dilakukan kapanpun sesuai dengan rancangan program yang dibuat guru. Pembelajaran outdoor dapat dilakukan saat pembelajaran normal, sebelum atau sesuai pembelajaran di sekolah, dan saat liburan sekolah (Silvia, 2015).

\section{METODE}

Penelitian ini menggunakan metode Research and Development (R\&D). Subyek penelitian ini adalah peserta didik kelas $X$ MIA SMAN 8 Kota Bengkulu. Prosedur penelitian terdiri atas 6 tahap yakni: 1) Potensi dan masalah; 2) Mengumpulkan informasi; 3) Desain produk; 4) Validasi desain; 5) Perbaikan desain ; 6) Uji coba produk. Teknik pengumpulan data menggunakan angket perilaku konservasi yang diberikan pada awal pembelajaran indoor 1 dan akhir pembelajaran indoor Perhitungan data validasi LKPD menggunakan rumus :

Persentase $=\frac{\text { Skor hasil pengukuran }}{\text { skor maksimal }} \times 100 \%$

(Sugiyono, 2008).

Rerata persentase hasil validasi ini kemudian diubah menjadi kategori kualitatif yang dapat dilihat pada Tabel 1.

Tabel 1. Kriteria Penilaian Hasil Validasi

\begin{tabular}{ll}
\hline Persentase & Kriteria \\
\hline $81 \%-100 \%$ & Sangat valid \\
$61 \%-80 \%$ & Valid \\
$41 \%-60 \%$ & Cukup valid \\
$21 \%-40 \%$ & Kurang valid \\
\hline
\end{tabular}

Tabel 2. Kriteria persentase upaya konservasi

\begin{tabular}{ll}
\hline Persentase & Kriteria \\
\hline $81 \%-100 \%$ & Sangat valid \\
$61 \%-80 \%$ & Valid \\
$41 \%-60 \%$ & Cukup valid \\
$21 \%-40 \%$ & Kurang valid \\
\hline
\end{tabular}

Skor angket untuk upaya konservasi peserta didik juga dipersentasekan menggunakan rumus:

Persentase $=\frac{\text { Skor peserta didik }}{\text { Skor maksimal }} \times 100 \%$

(Sugiyono, 2008). 
Rerata skor persentase peserta didik ini kemudian dikonversi ke kategori kualitatif dapat dlihat pada Tabel 2 .

\section{HASIL DAN PEMBAHASAN}

Hasil validasi menunjukkan LKPD yang didesain dalam kategori "Sangat baik". Persentase keidealan LKPD dari aspek kelayakan isi, dan kebahasaan diperoleh secara berurutan adalah $89,5 \%$ dan $95,5 \%$ dengan rerata keseluruhan sebesar $92,5 \%$ data hasil validasi dapat dilihat pada Tabel 3. Oleh sebab itu, LKPD hasil pengembangan dari penelitian identifikasi ancaman populasi lima jenis kura-kura sumatera layak untuk uji lapangan setelah revisi berdasarkan saran dari validator.

Tabel 3. Skor Validasi LKPD Identifikasi Ancaman Populasi Lima Jenis Kura-Kura Sumatera

\begin{tabular}{|c|c|c|c|c|c|c|c|}
\hline \multirow[b]{2}{*}{ No. } & \multirow[b]{2}{*}{$\begin{array}{c}\text { Komponen } \\
\text { yang } \\
\text { divalidasi }\end{array}$} & \multicolumn{3}{|c|}{ Skor } & \multirow[b]{2}{*}{ Rerata } & \multirow[b]{2}{*}{ Persentase } & \multirow[b]{2}{*}{ Kriteria } \\
\hline & & Dosen & Tim PEER & $\begin{array}{c}\text { Guru } \\
\text { Biologi } \\
\text { SMA }\end{array}$ & & & \\
\hline 1. & $\begin{array}{l}\text { Aspek } \\
\text { Materi (isi) } \\
\text { LKPD }\end{array}$ & 33 & 28 & 33 & 31,33 & $89,5 \%$ & Sangat valid \\
\hline 2. & $\begin{array}{l}\text { Aspek } \\
\text { Kebahasaan }\end{array}$ & 14 & 15 & 14 & 14,33 & $95,5 \%$ & Sangat Valid \\
\hline \multicolumn{5}{|c|}{ Rerata keseluruhan } & 45,66 & $92,5 \%$ & Sangat valid \\
\hline
\end{tabular}

Hasil uji keterbacaan LKPD oleh peserta didik mendapatkan nilai "Sangat Baik". Seluruh kriteria uji mendapatkan respon positif dari 15 peserta didik dengan skor rata-rata sebesar $89,25 \%$. Data hasil ui keterbacaan dapat dilihat pada Tabel.

Tabel 4. Hasil uji keterbacaan LKPD

\begin{tabular}{|c|c|c|c|c|c|c|c|c|}
\hline \multirow{2}{*}{$\begin{array}{l}\text { Jumlah } \\
\text { respon } \\
\text { peserta } \\
\text { didik }\end{array}$} & \multicolumn{2}{|c|}{$\begin{array}{l}\text { Komponen yang } \\
\text { divalidasi }\end{array}$} & \multicolumn{2}{|c|}{ Rerata } & \multicolumn{2}{|c|}{ Presentase } & \multicolumn{2}{|c|}{ Kriteria } \\
\hline & $\begin{array}{l}\text { Aspek } \\
\text { Materi } \\
\text { (isi) } \\
\text { LKPD }\end{array}$ & $\begin{array}{l}\text { Aspek } \\
\text { Kebaha } \\
\text { saan }\end{array}$ & $\begin{array}{l}\text { Aspek } \\
\text { Materi } \\
\text { (isi) } \\
\text { LKPD }\end{array}$ & $\begin{array}{l}\text { Aspek } \\
\text { Kebaha } \\
\text { saan }\end{array}$ & $\begin{array}{l}\text { Aspek } \\
\text { Materi } \\
\text { (isi) } \\
\text { LKPD }\end{array}$ & $\begin{array}{l}\text { Aspek } \\
\text { Kebaha } \\
\text { saan }\end{array}$ & $\begin{array}{l}\text { Aspek } \\
\text { Materi } \\
\text { (isi) } \\
\text { LKPD }\end{array}$ & $\begin{array}{l}\text { Aspek } \\
\text { Kebahas } \\
\text { aan }\end{array}$ \\
\hline 15 & 92 & 41 & 6,13 & 2,73 & $87,5 \%$ & $91 \%$ & $\begin{array}{l}\text { Sangat } \\
\text { Valid }\end{array}$ & $\begin{array}{l}\text { Sangat } \\
\text { Valid }\end{array}$ \\
\hline \multicolumn{3}{|c|}{ Rerata keseluruhan } & \multicolumn{2}{|c|}{8,86} & & $25 \%$ & \multicolumn{2}{|c|}{ Sangat valid } \\
\hline
\end{tabular}

Hasil pengisian angket upaya konservasi kura-kura peserta didik, melalui kegiatan indoor-outdoor-indoor (IOI) menunjukkan LKPD identifikasi ancaman populasi lima jenis kura-kura Sumatera efektif untuk meningkatkan upaya konservasi kura-kura bagi peserta didik. Nilai rata-rata perilaku upaya konservasi meningkat dari $58,6 \%$ menjadi $65,3 \%$ pada awal dan akhir kegiatan IOI. Data tersebut dapat dilihat pada Tabel 5. 
Tabel 5. Hasil angket upaya konservasi kura-kura

\begin{tabular}{cccc}
\hline $\begin{array}{c}\text { Jumlah Peserta Didik } \\
\text { Yang Mengisi Angket }\end{array}$ & $\begin{array}{c}\text { Presentase } \\
\text { Pemberian Angket } \\
\text { Awal }\end{array}$ & $\begin{array}{c}\text { Presentase } \\
\text { Pemberian Angket } \\
\text { Akhir }\end{array}$ & Kesimpulan \\
\hline 30 & $58,6 \%$ & $65,3 \%$ & Meningkat $27,03 \%$ \\
\hline
\end{tabular}

Penelitian ini menggunakan modul Pendidikan Konservasi Kura-kura Sumatera yang di dalamnya terdapat LKPD pada kegiatan indoor dan outdoor. Berdasarkan analisis yang dilakukan oleh peneliti, masih ada kekurangan pada LKPD tersebut, seperti butir pertanyaan yang kurang jelas, desain cover yang kurang menarik dan sulit dipahami, dan ada kalimat yang kurang jelas. Maka dari itu, peneliti melakukan revisi LKPD.

Hasil validasi dari dosen, tim PEER dan guru biologi SMA terhadap LKPD yang direvisi menunjukkan kategori "sangat valid". Artinya, LKPD yang dibuat sudah memenuhi kriteria dan layak diuji cobakan. Beberapa saran dari valdator adalah gambar sebaiknya menggunakan foto milik sendiri, ada pertanyaan yang perlu perbaikan, hindari penggunaan bullet dalam penomoran, cover perlu ditata agar lebih menarik, penulisan "ex-situ" ditulis miring tanpa tanda (-), kata-kata berbahasa asing ditulis miring, perbaiki penataan tabel, prosedur kegiatan dibuat lebih jelas, perbaiki susunan kata-kata dalam soal dan LKPD agar dibuat lebih singkat.

Menurut Salirawati (2011), LKPD hendaknya menggunakan struktur kalimat yang jelas, menggunakan kalimat yang sederhana dan pendek, dan menggunakan gambar yang efektif untuk menyampaikan pesan/ isi. Penampilan adalah hal yang sangat penting dalam LKPD. Pertama-tama peserta didik akan tertarik pada penampilan LKPD, bukan isinya. Apabila suatu LKPD ditampilkan dengan penuh kata-kata, kemudian ada pertanyaanpertanyaan yang harus dijawab oleh peserta didik, hal ini menimbulkan kesan jenuh sehingga membosankan dan tidak menarik. Apabila ditampilkan dengan gambar saja, itu tidak mungkin karena pesan/isinya tidak akan sampai. Jadi yang baik adalah LKPD yang memiliki kombinasi antara gambar dan tulisan.

Hasil uji keterbacaan untuk aspek materi (isi) LKPD ini adalah 87,5\%, sedangkan untuk aspek kebahasaan sebesar $91 \%$. Berdasarkan hasil validasi dan angket keterbacaan respon peserta didik, maka LKPD identifikasi ancaman populasi lima jenis kura-kura sumatera, sangat valid diimplementasikan kepada peserta didik.

Implementasi LKPD ini terhadap peserta didik kelas X MIA3 SMAN 8 Kota Bengkulu dapat meningkatkan upaya konservasi peserta didik. Hal ini sesuai dengan yang literatur yang menyebutkan bahwa pengetahuan dipandang sebagai sebuah tindakan yang bermakna untuk menganggulangi kendala-kendala psikologis seperti pengabaian dan kesalahan informasi. Meskipun pengetahuan tidak memiliki efek langsung pada perilaku target namun pengetahuan menjadi mekanisme tersendiri yang memberi fasilitasi pada perubahan perilaku (Pratkanis dan Turner,1994; dalam Firmiana 2012). Lebih lanjut Ruyani (2009) menyatakan bahwa pengetahuan merupakan faktor penting dalam mengembangkan beberapa sikap.

Pembelajaran mengenai kura kura yang dikaitkan dengan materi identifikasi ancaman populasi pada peserta didik SMA dimaksudkan untuk mengenalkan kurakura agar terhindar dari kepunahan. 
Pengajaran kepada peserta didik mengenai kura-kura, habitat dan ancamannya secara lokal dan global, merupakan salah satu usaha konservasi untuk melindungi kurakura di dunia (Matthews, dkk, 2018).

\section{PENUTUP}

\section{Simpulan}

Hasil validasi dan uji keterbacaan LKPD hasil pengembangan identifikasi ancaman populasi lima jenis kura-kura sumatera, menunjukkan LKPD ini sangat layak diujicoba. LKPD ini juga terbukti efektif meningkatkan perilaku upaya konservasi kura-kura bagi peserta didik.

\section{Saran}

Lembar kerja peserta didik ini dapat digunakan untuk penelitian tindakan kelas untuk meningkatkan sikap ilmiah siswa dengan kegiatan pembelajaran outdoor.

\section{DAFTAR PUSTAKA}

Firmiana, M.E, Rochimah I, Meithya R.P. 2012. "Go Green" Pelatihan untuk Mendorong Perilaku Konservasi Pro Lingkungan bagi Santri Al Ghazali Kota Bogor.(http://www.jurnal.uac.ac. id/.pdf diakses tanggal 12 Mei 2018)

KEMENHUT. 2012. Tentang Lembaga Konservasi.http://lpp.dephut.go.i d/downlot.php?file=1393595147 1393595151.pdf diakses pada tanggal 17 November 2017.

Majid, A. 2009. Perencanaan Pembelajaran. Bandung: PT Remaja Rosdakarya.

Prastowo, A. 2011. Panduan Kreatif Membuat Bahan Ajar Inovatif. Yogyakarta: Diva Press.

Rahmi, N. 2008. Pertumbuhan Juvenil LabiLabi, Amyda Cartilaginea(Boddaert, 1770) (Reptilia: Testudinata: Trionychidae) Berdasarkan
Pemberian Jenis Pakan Yang Berbeda, Dalam Upaya Domestikasi Untuk Menunjang Konservasi Di Desa Belawa, Kabupaten

Cirebon.http://msp.fpik.ipb.ac.id/ download/publikasi/ali mashar/ ART2009 AMA.pdf, diakses pada tanggal 16 Desember 2017

Rifa'i, Ahmad. 2012. Psikologi Pendidikan. Semarang: Unnes Press

Ruyani, A. 2015. Developing Science And Learning Research Capacity of Bengkulu University In Ex Situ Conservation of Sumatran Freshwater And Terrestrial Turtles. http: //sites. nationalacademies. org/ PGA/ PEER/ peerscience/ PGA 168049 diakses pada tanggal 07 Desember 2017.

Salirawati, S. 2011. Penyusunan Dan Kegunaan Lks Dalam Proses Pembelajaran. http: //staffnew .uny.ac.id/ upload/ 132001805/ pengabdian/19penyusunnandan-kegunaan-lks.pdf diakses pada tanggal 17 November 2017.

Silvia, T. 2015. Studi Pertumbuhan Awal Kura-kura Garis Hitam (Clyclemys oldhamii) di Lokasi Konservasi Taman Pintar Universitas Bengkulu dan Implementasinya Pada Pembelajaran Outdoor Siswa SD. TESIS. Bengkulu: Program Pasca Sarjana S2 Pendidikan IPA

Sinaga, H. 2008. Perdagangan Jenis-Jenis Kura-Kura Darat Dan Air Tawar Di Pasar Jakarta TESIS. Bogor: Institut Pertanian Bogor

Sugiyono. 2008. Metode Penelitian Kuantitatif Kualitatif dan $R \& D$. Bandung: Alfabeta

Suhartoyo, H, Anggraini, N,. Silviana, D.P,. dan Cempaka I. 2016. Pendidikan Konservasi Kura-Kura Sumatera. 
Diklabio: Jurnal Pendidikan dan Pembelajaran Biologi 3(1): 25-31 (Mei 2019) e-ISSN 2598-9669

Bengkulu: Fkip Unib Sugiyono. 2008. Metode Penelitian Kuantitatif Kualitatif dan $R \& D$. Bandung: Alfabeta
Wiryono. Alif, Y.Z dan Yemie, S. 2016. Pendidikan Konservasi Kura-kura Sumatera. Bengkulu: Unit Penerbit FKIP UNIB. 